\title{
A Ação Civil Pública em Matéria Tributária como Instrumento de Acesso à Justiça e Proteção dos Direitos Fundamentais dos Contribuintes
}

\author{
Deborah Moretti* \\ Yvete Flavio da Costa * *
}

\begin{abstract}
Introdução. 1.Os direitos fundamentais dos contribuintes. 1.1 Princípio da legalidade. 1.2 Princípio da isonomia. 1.3 Principio da irretroatividade tributária. 1.4 Principio da capacidade contributiva. 1.5 Principio da proibição ao confisco. 2. A natureza jurídica da relação tributária e a importância do processo coletivo na defesa dos contribuintes. 3 A (im)possibilidade da utilização da ação civil pública na defesa dos direitos fundamentais tributários. $4 \mathrm{~A}$ inconstitucionalidade da medida provisória 2180-35 de 2001. 5 A legitimidade do Ministério Público para a tutela coletiva, via ação civil pública, dos direitos fundamentais dos contribuintes; Conclusão; Referências.
\end{abstract}

\section{RESUMO}

Os direitos fundamentais tributários atuam como barreira de proteção ao arbítrio estatal, impondo limites à sua atuação tributante, e dignificando os sujeitos passivos da relação jurídico-tributária. Tendo em vista o caráter fundamental desses direitos, e sua natureza individual homogênea, deveriam ser resguardados aos contribuintes meios de acesso coletivo ao Judiciário para a tutela desses direitos, o que traria maior efetividade à jurisdição. A ação civil pública, disciplinada pela Lei 7347/85 é uma das formas de defesa dos direitos difusos,

* Advogada. Mestranda em Direito Público pelo Programa de Pós-Graduação em Direito da UNESP. Bacharela em Direito pela UNESP. Possui pesquisa em andamento, na temática Direito tributário coletivo, além de participações em eventos. Endereço do currículo Lattes: <http://lattes.cnpq.br/9571577483589415>email:deborahmoretti@gmail.com

** Graduação em Direito pela Universidade Federal Fluminense (1978), Mestre em Direito pela Pontifícia Universidade Católica de São Paulo (1993) e doutorado em Direito pela Pontifícia Universidade Católica de São Paulo (2002) e Pós-Doutoramento na Universidade de Coimbra - Portugal, sob supervisão do Professor Doutor José Manuel Aroso Linhares; Atualmente é professora Assistente Doutora na Universidade Estadual Paulista - "Júlio de Mesquita Filho” UNESP - Faculdade de Ciências Humanas e Sociais. Professora na Graduação e Pós-Graduação (mestrado) em regime de trabalho RDIDP, Líder do Núcleo de Pesquisas Avançadas em Direito Processual Civil e Comparado, Coordenadora do Curso de Especialização Lato-Sensu em Direito Processual Contemporâneo 1a Edição (2010-2011) e na 2a Edição (2011-2012). Coordenadora do projeto de extensão universitária na FCHS -UNESP - Educação - Orientação nas Escolas contra a prática do Bullying, Coordenadora do projeto de Estágio na Justiça Federal - projeto convênio entre a Universidade Estadual Paulista - UNESP - campus de Franca e o Tribunal de justiça Federal de São Paulo”. Endereço do currículo Lattes: <http://lattes.cnpq.br/0704127794367962> email: yvetecosta@gmail.com 
coletivos e individuais homogêneos possibilitada aos lesados por ações ou omissões, públicas ou privadas, que ultrapassam a dimensão da esfera individual. Ou seja, esse instrumento processual permite a tutela daqueles atos que atentam contra o pleno exercício de direitos transindividuais. No entanto, a Medida Provisória 2180-35, de 2001, acrescentou o parágrafo único no artigo $1^{\circ}$ da mencionada lei, aduzindo que não será cabível ação civil pública para veicular pretensões que envolvam tributos, contribuições previdenciárias, o Fundo de Garantia do Tempo de Serviço - FGTS ou outros fundos de natureza institucional cujos beneficiários podem ser individualmente determinados. Essa medida provisória é maculada por nítida inconstitucionalidade, e serve tão somente para limitar o acesso à justiça daqueles que se viram prejudicados pelo arbítrio estatal em sua ânsia arrecadatória. Com isso em mente, o presente artigo tem por escopo analisar a possibilidade do instituto da ação civil pública em matéria tributária como forma de acesso à justiça e de defesa dos direitos fundamentais dos contribuintes que são lesados coletivamente pelo Estado.

Palavras chave: Ação Civil Pública. Direitos fundamentais dos contribuintes. Acesso à justiça. Direito tributário.

\section{INTRODUÇÃO}

A problemática principal do presente trabalho se pauta na discussão acerca da possibilidade de existência de ação civil pública para a tutela dos direitos dos contribuintes, defendendo-se, especialmente, a legitimidade do Ministério Público para tanto, apesar de proibição legal e entendimento majoritário jurisprudencial nesse sentido. Serão expostos argumentos no sentido de demonstrar como essa proibição se mostra ilógica em relação ao sistema de proteção às demandas coletivas, já que tem por base norma inconstitucional, qual seja, a Medida Provisória 2180-35, de 2001, que aduz não ser cabível ação civil pública para veicular pretensões que envolvam tributos, contribuições previdenciárias, o Fundo de Garantia do Tempo de Serviço - FGTS ou outros fundos de natureza institucional cujos beneficiários podem ser individualmente determinados.

A importância de enfrentar esse paradigma, de tentar quebrá-lo, é decorrente do fato dele implicar na limitação do acesso à justiça que essa norma introduz a uma classe determinada de sujeitos, quais sejam, os contribuintes.

Os ganhos trazidos por essa discussão para a sociedade ou para a comunidade acadêmica são a exposição de um ponto de vista mais justo aos direitos daqueles que tem o acesso à justiça mitigado.

O objetivo central da presente pesquisa é o de demonstrar que uma eficaz via de acesso coletivo ao Judiciário tem sido limitada desarrazoada- 
mente, já que calcada numa normatização de cunho inconstitucional. Ou seja, que a proteção judicial aos direitos fundamentais dos contribuintes, de forma coletiva, foi mitigada por uma Medida Provisória inconstitucional, e que apesar de atentatória e limitativa do acesso à justiça, é corroborada pelo entendimento jurisprudencial.

Os objetivos específicos são os de analisar, de forma pormenorizada sucinta, os direitos fundamentais dos contribuintes contidos na Constituição Federal; contextualizar a tutela desses direitos para a existência de uma tributação justa; debater acerca de como a violação a esses direitos ultrapassam a esfera meramente individual, face à natureza da obrigação tributária, que atinge todos aqueles que se encaixam na descrição normativa da hipótese de incidência; discutir sobre a possibilidade de existência de ação civil pública para defesa desses direitos, face à natureza deles, apesar de dispositivo legal e entendimento jurisprudencial contrários; expor o entendimento majoritário da doutrina que entende ser possível o uso da ação civil pública para a defesa desses valores fundamentais; analisar como essa limitação ao uso da ACP configura limitação do acesso à justiça para os contribuintes que sofreram violações em sua esfera de direitos; discutir a inconstitucionalidade da Medida Provisória 2180-35, de 2001, que inseriu o paragrafo único no artigo $1^{\circ}$ da Lei 7347/85; discutir a importância do processo coletivo na efetivação do direito do acesso à justiça;

Justifica-se, assim, a escolha do tema, pela importância da efetivação e observância dos direitos dos contribuintes para uma tributação justa, devendo então a sistemática jurisdicional proporcionar todos os meio possíveis para a tutela desses direitos, garantindo o real acesso à justiça para os contribuintes.

A garantia da cientificidade da pesquisa está diretamente relacionada à determinação dos métodos de estudos, assim como dos materiais que serviram de marco teórico para a realização do trabalho de investigação. Neste ponto, serão expostos os principais métodos e materiais que irão ser utilizados no estudo teórico em voga, sem prejuízo outros que porventura venham a ser utilizados ao longo do desenvolvimento da pesquisa.

Tendo em vista o caráter teórico da pesquisa a ser realizada, o material preponderantemente utilizado será o bibliográfico. Assim, ao longo do desenvolvimento da pesquisa, foram utilizados livros que enfoquem os aspectos teóricos do tema.

Por se tratar de pesquisa de assunto que não é pacífico, já que a doutrina majoritária entende pela possibilidade da ação civil pública ser utilizada para defender os direitos dos contribuintes, enquanto os tribunais refutam essa tese, foram utilizados livros que tratem do assunto, e que exponham os argumentos a favor, como os contrários, que foram expostos ao longo do trabalho. Teve também amplo espaço no trabalho a utilização de artigos científicos que também debatam o aqui em voga, face a interdisciplinariedade do tema em estudo.

Ademais, face a interdisciplinaridade do assunto, não foram somente utilizados materiais que tratem acerca do direito tributário tão somente, se pautando 
a pesquisa no estudo do direito processual individual e coletivo, além do direito constitucional, nos temas atinentes ao aqui em análise.

De forma a possibilitar o aprofundamento temático do assunto, pretende-se empregar os métodos lógico-dedutivo, já que a pesquisa terá por base a comparação dos diferentes entendimentos sobre o tema, de forma a demonstrar qual seria o mais benéfico ao contribuinte.

\section{OS DIREITOS FUNDAMENTAIS DOS CONTRIBUINTES}

Os direitos fundamentais, em virtude de sua natureza atinente à condição humana, são valores universais, antecedendo até mesmo, todas as formas de organização política. Por conta disso, sua proteção não se esgota na ação do Estado. São universais e absolutos, pois são determinados pela razão, a partir de princípios como a liberdade e a dignidade de todo ser humano, ou seja, devem ter observância garantida a todos, sem quaisquer distinções.

Em virtude dessa premissa, os direitos fundamentais formam o cerne mais valioso dentre os direitos previstos, pois tutelam valores que, estando umbilicalmente ligados à proteção individual, se relacionam diretamente à vida, à liberdade, à igualdade, com todos os desdobramentos atinentes a essa proteção.

Bonavides acredita que os direitos fundamentais são os do ser humano que as Constituições positivaram, recebendo nível mais elevado de garantias ou segurança. Cada Estado, pois, tem seus direitos fundamentais específicos. $\mathrm{O}$ autor ainda acrescenta que os direitos fundamentais estão vinculados aos valores de liberdade e dignidade humana, levando-nos, assim, ao "significado de universalidade inerente a esses direitos como ideal da pessoa humana". ${ }^{1}$

Dentre os direitos fundamentais, ou seja, aqueles inerentes à condição de pessoa humana, se encontram os direitos e garantias dos contribuintes. Esses direitos atuam como barreira de proteção ao arbítrio estatal, impondo limites à sua atuação tributante, e dignificando os sujeitos passivos da relação jurídico-tributária.

Em virtude da existência dessas garantias institucionais, a Administração Tributária, assim como os legisladores, seja na esfera federal, estadual ou municipal, ao fazerem uso de suas competências tributárias, estão obrigados a respeitar os direitos e garantias individuais, de forma que o contribuinte tenha o direito de, ainda que tributado pela pessoa política competente, ter respeitado seus direitos públicos subjetivos, constitucionalmente garantidos. ${ }^{2}$

A interpretação e implementação dos direitos fundamentais estariam, em geral, a cargo dos sistemas políticos nacionais. ${ }^{3}$ Ou seja, a proteção e promoção dos direitos fundamentais no foro doméstico deveria se dar como resultado da atividade do Estado social e democrático de direito. 
Ademais, a proteção dos direitos fundamentais pelo Estado seria decorrência do pacto constitucional, pois eles são a expressão daquelas condições essenciais para o funcionamento de um Estado democrático de direito. Seriam, assim, fundamentais, no sentido de que, a violação daquelas seria, por si mesma, sinal da ausência estatal ${ }^{4}$, já que os estados são os atores determinantes na efetivação ou não dos direitos humanos. Ou seja, a efetividade dos direitos humanos é dependente de vontade estatal nesse sentido, e da ausência de violação destes pelos detentores do poder.

À Ordem política é atribuída a responsabilidade de reconhecer/proteger/ promover os direitos fundamentais. Percebe-se que essa proteção é decorrente de um procedimento continuo, ou seja, não basta apenas reconhecer esses direitos, mas deve-se também proteger e promover a sua real efetivação, já que a ausência dela pode dar origem a graves violações.

Para tornar efetivos os direitos fundamentais, o Estado é sempre chamado a agir de alguma forma. Não existe uma suposição de que seja possível assegurar direitos humanos sem algum tipo de institucionalização que passe pelos mecanismos conhecidos do Estado. ${ }^{5}$

As previsões constitucionais conferem unidade ao sistema jurídico e o direito processual assegura o exercício das funções estatais, conferindo efetividade às garantias constitucionais. $\mathrm{O}$ acesso à justiça, enquanto garantia constitucional, implica no atendimento processual dos cidadãos em juízo, e esse atendimento é fulcrado na proteção aos direitos fundamentais. Não há como afastar o seu entendimento da ideia de Constituição. A Constituição Federal Brasileira de 1988, entre todas, foi a que mais se preocupou com a defesa dos cidadãos em juízo, tanto individualmente como de forma coletiva, estabelecendo princípios fundamentais para um processo justo (considerado aqui como aquele que pretende assegurar o bem da vida a quem de direito, utilizando-se dos mecanismos mais adequados). Neste sentido, o acesso à justiça não deve ser, tão somente, quantitativo, mas qualitativo, não podendo afastar-se das regras constitucionais, cuja maior função é proteger as garantias dos cidadãos, coletiva e individualmente. ${ }^{6}$

O conjunto de direitos e garantias dos indivíduos diante da instituição, arrecadação e fiscalização de tributos é constitucionalmente estabelecido e forma o que a doutrina denomina de "estatuto do contribuinte". O estatuto do contribuinte exige que a tributação, livre de qualquer arbitrariedade, realize a ideia de Estado de Direito. Às várias possibilidades de atuação da Fazenda Pública há de corresponder a garantia dos direitos individuais fundamentais de cada contribuinte. Quanto mais gravosa a intervenção tributária, tanto mais cuidadosamente deverá ser protegida a esfera de interesses dos indivíduos. ${ }^{7}$

Os direitos fundamentais tributários vem positivados, na Constituição Federal, a partir do artigo 150 , sem excluir aqueles previstos no artigo $5^{\circ}$. Eles estão previstos como limitações constitucionais ao poder de tributar.

No Brasil, o reconhecimento em caráter específico dos direitos dos contribuintes como fundamentais possui algumas peculiaridades. Primeiramente, 
dada a previsão do princípio da legalidade e da anterioridade entre os direitos individuais na Constituição de 1967, com a Emenda de 1969 (art. 153, § 29) que, como norte de interpretação histórica, revela uma orientação do sistema positivo que, face ao nível ampliado de proteção da Constituição vigente, não tenderia a enfraquecer, mas sim em consolidar e ampliar o teor de segurança jurídica para as relações tributárias entre Estado e contribuintes. Em segundo lugar, pela força emanada de decisão paradigmática do Supremo Tribunal Federal que enquadrou o princípio da anterioridade dentro da categoria dos direitos fundamentais (ADI n 939-7), justificando a inclusão no art. $5^{\circ}, \S 2^{\circ}$, com ofensa ao art. $60, \S 4^{\circ}$, todos da Constituição Federal, o que importa na utilização do conceito de direitos fundamentais no sentido material, ou seja, de uma concepção que reconhece como fundamentais direitos constantes em outros pontos da Constituição, para além do rol do art. $5^{\circ} .{ }^{8}$

Como decorrência de um conceito material de direitos fundamentais, os direitos dos contribuintes constantes do lado de fora do catálogo (arts. 150 a 152 , da CF), por força da cláusula de abertura contida no $\S 2^{\circ}$ do art. $5^{\circ}$, que não exclui outros direitos decorrentes do regime e dos princípios adotados, passam a integrar a categoria dos direitos fundamentais. Assim, defendemos uma classificação dos direitos fundamentais dos contribuintes embasada no art. 5० da Constituição Federal que ressalta como objeto de proteção o direito à vida, à liberdade, à segurança e à propriedade ${ }^{9}$. De forma a contextualizar-se o objeto de estudo aqui investigado, passa-se à análise sucinta de cada um dos direitos fundamentais tributários.

\subsection{Princípio da legalidade}

O princípio da legalidade na esfera tributária vem previsto no artigo 150, I da Norma Fundamental, e proíbe que seja exigido ou aumentado tributo sem lei que assim o estabeleça. Esse dogma fundamental também vem previsto no artigo 97 do Código Tributário Nacional ${ }^{10}$ e significa pressuposto de observância obrigatória, tanto pelo legislador positivo, como pelo ente que realiza a arrecadação e fiscalização do tributo. Decorrência direta desse princípio, é a existência do postulado da tipicidade cerrada. Em virtude dele, todos os aspectos de incidência tributária (regra matriz) devem estar descritas na lei de forma determinada ou determinável, de forma a conferir segurança jurídica na tributação.

A regra matriz de incidência é composta pelo aspecto material, aspecto espacial, aspecto temporal, aspecto pessoal e aspecto quantitativo. $\mathrm{O}$ aspecto material consiste na descrição legal do fato típico tributário, e é consubstanciada pela previsão, na lei do verbo e complemento que identifica a conduta a ser tributada. $\mathrm{O}$ aspecto espacial consiste no local de ocorrência do fato gerador, e é importante para a definição da competência tributária, da capacidade ativa tributária, e do domicílio tributário, quando este não é eleito pelo contribuinte. Já o aspecto temporal configura o momento da ocorrência do fato gerador. O aspecto pessoal define quem será colocado no polo passivo da relação jurídico 
tributária, ou seja, quem sofrerá a constrição patrimonial decorrente da obrigação tributaria. Por fim, o aspecto quantitativo determina o valor que será destinado aos cofres públicos, e consiste na alíquota e na base de cálculo.

Cabe ressaltar que os aspectos material, espacial e temporal são antecedentes normativos, ou seja, apesar de, necessariamente, deverem vir previstos em lei, sua existência não é dependente da configuração do fato gerador. Já os aspectos pessoal e quantitativo, dependem da ocorrência do fato gerador para sua determinação, consubstanciando o consequente normativo.

\subsection{Princípio da isonomia}

O princípio fundamental da isonomia vem previsto no artigo 150, II da Constituição Federal, e é corolário da igualdade prevista no artigo $5^{\circ}$ do referido diploma, e impõe que é é vedado à União, aos Estados, ao Distrito Federal e aos Municípios instituir tratamento desigual entre contribuintes que se encontrem em situação equivalente, proibida qualquer distinção em razão de ocupação profissional ou função por eles exercida, independentemente da denominação jurídica dos rendimentos, títulos ou direitos.

\subsection{Princípio da irretroatividade tributária}

O princípio da irretroatividade tributária, previsto no artigo 150, III, a, da Constituição Federal comina que a lei a ser aplicada é aquela vigente a época do fato gerador. $\mathrm{O}$ paragrafo $1^{\circ}$ do artigo 144 do Código Tributário. Assim, quando ocorre violação desse artigo que não se encontre configurada nas exceções previstas legalmente, restará configurada conduta arbitrária por parte do ente estatal competente para a instituição do tributo, ensejando a reparação jurídica ou administrativa. ${ }^{11}$

\subsection{Princípio da capacidade contributiva}

O princípio da capacidade contributiva, previsto no parágrafo $1^{\circ}$ do artigo 145 da Constituição Federal aduz que sempre que possível, os impostos terão caráter pessoal e serão graduados segundo a capacidade econômica do contribuinte. Assim, o critério da seletividade é uma das técnicas de tributação expressamente previstas na $\mathrm{CF} / 88$ para a concretização do principio da capacidade contributiva. Outro instrumento para a consecução desse principio é a progressividade tributária, por meio do qual, a partir do momento em que ocorre o aumento da base de cálculo de um determinado tributo, ocorre o aumento na alíquota deste.

\subsection{Princípio da proibição ao confisco}

Como outra garantia fundamental disposta ao contribuinte, encontra-se o principio da proibição do confisco, previsto no artigo 150, IV da Constituição Federal. Por meio deste, ficam vedadas tributações excessivas que acarretem a 
inviabilidade econômica do contribuinte. Assim, a tributação deverá observar parâmetros de proporcionalidade e razoabilidade.

\section{A NATUREZA JURÍDICA DA RELAÇÃO TRIBUTÁRIA E A IMPOR- TÂNCIA DO PROCESSO COLETIV̉O NA DEFESA DOS CONTRI- BUINTES}

O que se tentou provar a partir da análise desses institutos é que sempre que um desses princípios fundamentais não é observado na instituição de um tributo, ou mesmo em sua fiscalização ou arrecadação, não será tão somente um individuo quem sofrerá com a mitigação de seus direitos fundamentais, já que a obrigação tributária deve ser adimplida por todos aqueles que se encontram na situação descrita na hipótese de incidência.

Ocorre que, pela natureza da relação jurídico tributária, que atinge não tão somente um indivíduo, mas o conjunto daqueles que se encaixam na hipótese de incidência descrita no fato gerador, quando uma norma que imponha uma obrigação tributária nasça eivada de vício, que atente contra um direito fundamental do contribuinte, refletirá não somente na esfera jurídica tão somente de um indivíduo, mas de todos que se enquadram naquela situação. Dessa forma, para não se congestionar o já tão saturado Judiciário brasileiro, deveriam ser previstos mecanismos processuais que defendessem esses direitos fundamentais de forma coletiva.

Assim, na relação jurídico tributária, ocorre, notadamente, uma transmutação dos interesses que, num primeiro momento, tem cunho individual, para a esfera coletiva, face a natureza cogente e imperativa da obrigação tributária, que não atinge tão somente uma determinada pessoa. Por isso, devem ser previstas formas procedimentais que permitam um engajamento garantista coletivo na proteção desses direitos no âmbito do Judiciário.

Ao se cogitar acerca possibilidade de proteção coletiva em matéria tributária, deve-se levar em consideração, necessariamente, dois conceitos: o de obrigação tributária principal e o de direito individual de origem homogênea, cuja tutela pertence ao Ministério Público. ${ }^{12}$

A obrigação tributária constitui a própria relação jurídica, consubstanciada entre o Ente Político (credor, sujeito ativo) e o contribuinte (devedor, sujeito passivo). Ou seja:

[...] é a relação jurídica em virtude da qual o particular (sujeito passivo) tem o dever de prestar dinheiro ao Estado (sujeito ativo), ou de fazer, não fazer ou tolerar algo no interesse da arrecadação ou da fiscalização dos tributos, e o Estado tem o direito de constituir contra o particular um crédito. ${ }^{13}$

Pode-se afirmar que a obrigação tributária é de natureza pública e calcada no princípio da legalidade tributária, ou seja, tem origem, necessariamente, 
na lei. Nos dizeres de Marcio Cesar Costa, "a obrigação tributária consiste no vínculo jurídico estabelecido entre um sujeito passivo e um sujeito ativo sendo que o primeiro ficará obrigado a realizar uma prestação ao segundo" 14

No diploma tributário nacional em vigor (Lei 5.172/66), a obrigação tributária é disciplinada em seu artigo $113 \S \S 1^{\circ}$ a $3^{\circ}{ }^{15}$. Para se entender por completo tal instituto, deve ser apreciado também o elemento objetivo da relação obrigacional, qual seja, a prestação econômica, positiva ou negativa, que no Direito Tributário se divide em obrigação acessória e obrigação principal.

A obrigação principal se configura na obrigação jurídica de implemento da obrigação tributária trazida pelo tributo ou penalidade pecuniária, conforme disciplinado no $§ 1^{\circ}$ do art. 113.

Essa modalidade obrigacional se sucede a partir da ocorrência do fato tipificado pela lei em sentido estrito, a qual, ao conter todos os elementos necessários a sua regular constituição, tem o condão de fazer surgir o dever legal do pagamento do tributo por parte do contribuinte. É o que se entende da exegese literal do artigo 114 do Código Tributário Nacional (CTN), nos termos do qual, fato gerador da obrigação principal corresponde a situação definida em lei como necessária e suficiente à sua ocorrência.

A obrigação tributária é obrigação ex lege, ou seja, calcada em lei. Essa derivação direta da lei é importante dado inicial a ser levado em conta na análise sobre a possibilidade de ação civil pública em matéria tributária. ${ }^{16}$

Direito individual homogêneo, por sua vez, conforme será melhor explorado posteriormente, são aqueles decorrentes de origem comum, que advêm da própria lesão, ou ameaça de lesão, em que a relação jurídica entre as partes é post factum (fato lesivo). Não se mostra necessário, contudo, que esse fato se dê em um só lugar ou momento histórico, mas que dele decorra a homogeneidade entre os direitos dos diversos titulares de pretensões individuais. ${ }^{17}$

Em outras palavras, os direitos individuais de origem homogênea traduzem direitos supraindividuais, mas essa supraindividualidade não é intrínseca a esses direitos, constituindo, então, direitos individuais e disponíveis. Embora disponíveis, são direitos tuteláveis mediante ação civil pública, dentre outros instrumentos de acesso coletivo à justiça. ${ }^{18}$

As leis que tutelam essa espécie de direitos recomendam a eles um tratamento de forma coletiva, por razões de segurança jurídica, quais sejam, previsibilidade das consequências de uma dada conduta e impedimento da prolação de decisões conflitantes. Isso porque, se cada lesado for buscar a tutela de seu direito, que é exatamente igual à de outro indivíduo, atingido pela mesma situação fática, existirá uma imensa multiplicidade de ações idênticas, com grande probabilidade de prolação de decisões diferentes. ${ }^{19}$

O tratamento coletivo a direitos individuais e disponíveis, desde que tenham origem homogênea, é questão de interesse público, denotado pelo 
caráter eminentemente público da relação jurídico tributária, que tem como sujeito ativo um ente político. É por isso que esses direitos, não obstante individuais e disponíveis, são passíveis de tutela mediante ação civil pública e, portanto, o Ministério Público tem legitimidade para defendê-los. ${ }^{20}$

Associadas as duas ideias preliminares - a de obrigação tributária ex lege e a do princípio da generalidade da tributação - e considerados os direitos individuais de origem comum, exsurge, com clareza, que relações obrigacionais tributárias vão gerar, com frequência, direitos individuais de origem homogênea. Se, por exemplo, há a exigência de tributo e se a impugnação que se faz é a de que a lei que o institui não observa princípios constitucionais, como tal relação reveste-se de natureza ex lege e como há o atributo da generalidade da tributação, o vício legal existente atingirá múltiplas relações jurídicas idênticas. ${ }^{21}$

Assim, o acesso à justiça possibilitado por meio do processo coletivo se mostra fundamental na defesa desses direitos, pois a esmagadora maioria dos contribuintes lesados não vão tentar, individualmente, procurar o ressarcimento daquilo que foi pago indevidamente, ou, igualmente, procurar algum meio (no Judiciário) de não pagar o valor que está sendo cobrado, e ele entende ser indevido, tanto por inconstitucionalidade, ou por apenas ilegalidade. ${ }^{22}$ Isso porque as tutelas coletivas foram criadas para que haja uma maior proteção da coletividade. Em um verdadeiro Estado Democrático de Direito faz-se mister a existência e possibilidade de meios apropriados e adequados na defesa dos cidadãos. ${ }^{23}$

Torna-se necessário, então, aparelhar a sociedade com instrumentos mais adequados para a tutela dos direitos individuais que, tendo uma mesma origem e semelhança, seriam mais bem tutelados se o fossem coletivamente, na busca da celeridade e economia processuais, sem perder de vista a segurança jurídica dos jurisdicionados. ${ }^{24}$

\section{A (IM)POSSIBILIDADE DA UTILIZAÇÃO DE AÇÃO CIVIL PÚBLICA NA DEFESA DOS DIREITOS FUNDAMENTAIS TRIBUTÁRIOS}

Um desses remédios que poderiam ser utilizados para a proteção coletiva dos direitos fundamentais individuais dos contribuintes é a ação civil pública, que constitui um instrumento constitucional que visa a tutelar direitos coletivos lato sensu, e tem por finalidade a tutela coletiva do patrimônio público e social, do meio ambiente e de outros interesses difusos e coletivos, e que teve origem, no Brasil, com a promulgação da Lei 7.347/85. Trata-se, assim, de uma ação coletiva, que por meio do processo coletivo, tem por escopo a defesa dos direitos transindividuais em sentido amplo.

Com a promulgação da Constituição da República de 1988, esse instrumento processual ganhou maior projeção dentro do ordenamento jurídico brasileiro, já que seu art. 129, III dispõe que é função institucional do Ministério Público promover o inquérito civil e a ação civil pública, para 
a proteção do patrimônio público e social, do meio ambiente e de outros interesses difusos e coletivos.

A ação civil pública pode então ser entendida como um mecanismo processual que pode ser acionado pelas pessoas e entes expressamente elencados pela Lei n. ${ }^{\circ}$ 7.347/85, visando à proteção de interesses grupais (ou seja, difusos, coletivos e individuais homogêneos), seja porque a tutela jurisdicional individual seria (quase) impossível, seja porque ela seria antieconômica e menos eficaz. ${ }^{25}$

Esse remédio processual tem por fim proteger o interesse transindividual da coletividade, aquele que não está restrito a esfera individual. No âmbito da proteção ao meio ambiente, ao consumidor, infância e juventude, urbanismo, pessoa portadora de deficiência, dentre muitos outros temas, a ação civil pública ganhou destaque como inovador e eficiente instrumento de tutela jurisdicional de direitos e interesses metaindividuais, sendo hoje largamente utilizada ${ }^{26}$ para tutelar aqueles direitos que escapam à esfera individual.

Nesta seção do presente trabalho, cabe realizar a diferenciação entre os direitos difusos, direitos coletivos stricto sensu e direitos individuais homogêneos. Nos dizeres de Didier e Zaneti Júnior:

Denominam-se direitos coletivos lato sensu os direitos coletivos entendidos como gênero, dos quais são espécies: os direitos difusos, os direitos coletivos stricto sensu e os direitos individuais homogêneos. Em conhecida sistematização doutrinária, haveria os direitos/interesses essencialmente coletivos (difusos e coletivos em sentido estrito) e os direitos acidentalmente coletivos (individuais homogêneos). ${ }^{27}$

Já os interesses ou direitos difusos são aqueles direitos que apresentam indivisibilidade, ou seja, é impossível satisfazer seus titulares de forma individual, pois estes são indeterminados. São aqueles direitos transindividuais, de que são titulares pessoas ligadas por circunstancias de fato. Assim, o objeto desses direitos são indivisíveis, e seus titulares não podem ser determinados, estando vinculados por situações fáticas, e não jurídicas.

Justamente no aspecto origem é que reside a diferença básica entre os direitos ou interesses difusos e os direitos ou interesses coletivos em sentido estrito. Nos direitos ou interesses difusos não existe prévia relação jurídica base, pois as pessoas estão ligadas por meras circunstâncias fáticas, ao passo que nos coletivos é fundamental a existência de prévia relação jurídica base entre os membros da categoria, classe ou grupo de pessoas ou entre essas pessoas e a parte contrária. ${ }^{28}$

Esses direitos são indetermináveis, tendo em vista que não é possível mensurar quantas e quais pessoas efetivamente foram atingidas pela situação de fato que ensejou o dano sofrido. ${ }^{29}$ 
Essa "indeterminação de sujeitos" deriva, em boa parte, do fato de que não há um vínculo jurídico coalizador dos sujeitos afetados por esses interesses: eles se agregam ocasionalmente, em virtude de certas contingências, como o fato de habitarem certa região, de consumirem certo produto, de viverem numa certa comunidade, por comungarem pretensões semelhantes, por serem afetados pelo mesmo evento originário de obra humana ou da natureza etc. [...] Quer dizer, se o interesse é sempre uma relação entre uma pessoa e um bem (quod inter est), no caso dos interesses difusos essa relação é super ou metaindividual, isto é, ela se estabelece entre uma certa coletividade, como sujeito, e um dado bem de vida "difuso", como objeto. ${ }^{30}$

Os direitos coletivos lato sensu, assim como os direitos ou interesses difusos, também tem natureza indivisível, mas tem como titulares uma categoria ou classe de pessoas ligadas entre si ou com a parte contrária por uma relação jurídica base, que envolve sujeitos determinados ou determináveis. Assim, essa categoria de direitos apresenta indivisibilidade de objeto, mas nele existe a possibilidade de determinação de seus sujeitos, que se encontram ligados por um vínculo jurídico. "O traço característico e distintivo dessa modalidade de interesses é a 'organização', uma vez que, se não organizados, não ocorre a coletivização e a aglutinação em torno de interesses comuns.". ${ }^{31}$

Nessa categoria de direitos:

[...] se a sentença não puder ser tal que beneficie um membro da classe e ao mesmo tempo não beneficie outro membro da mesma classe, indivisível será o direito. Por outras palavras, se algum membro da classe puder pleitear para si certo bem jurídico sem que o sucesso de seu pleito aproveite aos outros membros da classe, não haverá indivisibilidade $[\ldots]^{32}$

Os direitos individuais homogêneos são os direitos de natureza individual e divisível, decorrentes de origem comum, e que tem como titulares pessoas determinadas ou determináveis.

Tanto os interesses individuais homogêneos como os difusos originam-se de circunstâncias de fato comuns; entretanto, são indetermináveis os titulares de interesses difusos, e o objeto de seu interesse é indivisível; já nos interesses individuais homogêneos, os titulares são determinados ou determináveis, e o objeto da pretensão é divisível (isto é, o dano ou a responsabilidade se caracterizam por sua extensão divisível ou individualmente variável entre as integrantes do grupo). [...] nos interesses individuais homogêneos, há sim uma origem comum para a lesão, fundada tanto numa situação de fato compartilhada pelos integrantes do grupo, como numa mesma relação jurídica que a todos envolva, mas, o que lhes dá a nota característica e inconfundível é que o proveito pretendido pelos integrantes do grupo é perfeitamente divisível entre os lesados. ${ }^{33}$

Referidos direitos, apesar de individuais, tem como situação originária o mesmo fato ou relação jurídica, o que justifica sua tutela coletiva, facilitando 
o acesso à Justiça e dando uma maior relevância jurídica ao dano sofrido pelos indivíduos. ${ }^{34} \mathrm{O}$ que ocorre é uma diferença essencial quanto à forma de tutela, de maneira que, para aqueles direitos que antes eram defendidos apenas por instrumentos do processo civil tradicional, abre-se a possibilidade de defesa através de um processo coletivo, com vistas à facilitação do acesso à justiça. Fica evidente que a tutela coletiva dos direitos individuais homogêneos não é uma imposição da natureza dos mesmos, mas uma forma de tutela mais adequada e eficaz.

A tutela coletiva do tema possibilita também uma melhor percepção da dimensão do dano provocado, o que não seria verificado caso os direitos fossem tutelados individualmente. É nesse rol que se encaixam os direitos dos contribuintes, pois, apesar de individuais, detém origem homogênea, qual seja, a arbitrariedade do poder público que deu origem a violação de algum princípio constitucional.

Apesar disso, os direitos e garantias dos contribuintes, mesmo que incluídos na classe dos metaindividuais (individuais homogêneos) já que atingem a esfera jurídica de mais de uma pessoa, e tem origem comum, não recebem a necessária proteção por meio da ação civil pública, isto porque, com base no disposto no parágrafo único do artigo $1^{\circ}$ da Lei da ACP, que aduz não ser cabível ação civil pública para veicular pretensões que envolvam tributos, contribuições previdenciárias, o Fundo de Garantia do Tempo de Serviço - FGTS ou outros fundos de natureza institucional cujos beneficiários podem ser individualmente determinados, foi construído um entendimento jurisprudencial que não permite o alcance da tutela visada pela ACP a esses direitos.

No entanto, a doutrina especializada no tema prevê a possibilidade de utilização desse instituto para defender os direitos fundamentais dos contribuintes, naquelas relações em que os direitos escapam à esfera do individualismo, face à natureza coletiva da obrigação tributária, que atinge a todos que se encaixem na hipótese de incidência, já que essa majoritária posição jurisprudencial não encontra guarida na Constituição Federal, que contemplou a ação civil pública como meio de defesa de qualquer interesse difuso e coletivo (art. 129, inciso III), de forma que existe a necessidade de urgente revisão de tal posição, especialmente em nossos tribunais superiores. ${ }^{35}$

E esse entendimento é fulcrado, notadamente, na inconstitucionalidade da Medida Provisória 2180-35 de 2001, que inseriu a proibição legal, assim como na legitimidade do Ministério Público para a defesa dos interesses individuais homogêneos em juízo.

\section{A INCONSTITUCIONALIDADE DA MEDIDA PROVISÓRIA 2180-35 DE 2001}

Instrumento normativo que teve origem com a promulgação da Constituição Federal de 1988, a Medida Provisória assumiu função de extrema relevância no ordenamento jurídico do país ao longo dos últimos anos. A prodigalidade do Poder Executivo em editar Medidas Provisórias, que muitas vezes não observava 
os requisitos constitucionais - e nisto contando com o beneplácito do Poder Judiciário - transmudou tal instrumento em veículo de comandos normativos os mais variados, editados pelo Chefe do Poder Executivo, em explícita usurpação de competência imanente ao Congresso Nacional. Essa prática se afigura ainda mais nefasta quando se utiliza a Medida Provisória para suprimir direitos e garantias dos cidadãos, ou para modificar matéria privativa de lei complementar. É a hipótese da Medida Provisória no ${ }^{1.984-18}$, que submetida a repetidas reedições, corresponde atualmente à Medida Provisória no 2.180-35. ${ }^{36}$

A Medida Provisória 2180-35 de 2001, que ao acrescentar o paragrafo único ao artigo $1^{\circ}$ da Lei da Ação Civil Pública, serviu para restringir a utilidade desse instrumento é eivada de nítida inconstitucionalidade, e acaba por restringir o acesso à justiça por parte daqueles que tem sua esfera de direitos fundamentais lesada. Isso porque ela é contrária ao disposto no artigo 62 da Constituição Federal de 1988, que disciplina ser vedada a edição de medidas provisórias sobre matéria direito penal, processual penal e processual civil. Tendo em vista que a Lei de Ação Civil Pública traz normas sobre o direito processual civil coletivo, esta medida provisória apresenta legítima afronta ao texto maior.

Assim, mostra-se de controvertida constitucionalidade a referida Medida Provisória, que cuida de suprimir dos cidadãos o direito de serem defendidos por órgãos e entidades dotados de estrutura adequada e especializada, que suprirão as deficiências econômicas e de instrução dos contribuintes lesados. A estes vale estender, por analogia, o predicado da hipossuficiência reconhecida aos consumidores, representando os contribuintes a "parte mais fraca" da relação jurídica estabelecida com o Poder Público, fazendo jus ao direito de serem assistidos e verem seus interesses tutelados pelo Ministério Público e associações, através de instrumentos processuais eficazes, como meio de reequilibrar o embate de forças com o sujeito ativo da relação tributária ${ }^{37}$.

\section{A LEGITIMIDADE DO MINISTÉRIO PÚBLICO PARA A TUTELA COLETIVA, VIA AÇÃO CIVIL PÚBLICA, DOS DIREITOS FUNDA- MENTAIS DOS CONTRIBUINTES}

Assim, apesar da existência dessa Medida Provisória, que limitou o âmbito de incidência da proteção visada pela ação civil pública, muitas vezes o Ministério Público, ao se deparar com situações em que os direitos coletivos dos contribuintes são violados, utiliza esse remédio processual para a tutela de direitos de cunho notadamente coletivo, mas é rechaçado pelos tribunais, que, levando em consideração a previsão legal, afastam qualquer tentativa do parquet nesse sentido.

A legitimidade para a propositura da ação civil pública vem disciplinada no artigo $5^{\circ}$ da Lei $7347 / 85^{38}$, sendo também prevista no artigo 82 do Código de Defesa do Consumidor ${ }^{39}$.

A legitimidade ativa é concorrente, já que sua propositura pode ser atribuída a diversos agentes previstos em lei, e disjuntiva, já que quaisquer dos 
legitimados podem vir a atuar efetivamente em juízo. No que concerne à legitimidade passiva, podem ser réus da ação civil pública tanto pessoas e órgãos da Administração Pública, como pessoas físicas e jurídicas particulares. Para isso, basta que realizem ato nocivo ou potencialmente prejudicial a um interesse difuso ou coletivo tutelado pela ação civil pública.

O Ministério Público tem legitimidade para promover ação civil pública que vise defender os direitos difusos, coletivos e individuais homogêneos. Entretanto, o parquet somente terá representatividade adequada para propor a ACP se os direitos/interesses discutidos na ação estiverem relacionados com as suas atribuições constitucionais, que são previstas no art. 127 da CF que aduz que o Ministério Público é instituição permanente, essencial à função jurisdicional do Estado, incumbindo-lhe a defesa da ordem jurídica, do regime democrático e dos interesses sociais e individuais indisponíveis. Em virtude disso, o entendimento majoritário jurisprudencial pátrio colaciona que, no caso dos direitos difusos e coletivos lato sensu, o MP sempre possui representatividade adequada, e sempre poderá propor ação civil pública em defesa dessas modalidades de direitos.

Ademais, deve-se levar em conta o disposto no artigo $5^{\circ}$ da Lei Complementar no 75, de 20 de maio de $1993^{40}$, que dispõe sobre a organização, atribuições e estatuto do Ministério Público da União. Esse artigo cominou ao MPF o zelo pela observância dos princípios constitucionais relativos ao sistema tributário, às limitações do poder de tributar, à repartição do poder impositivo e das receitas tributárias e aos direitos do contribuinte. Essa disposição legal serve então para a confirmar a premissa de que o MP deverá atuar como legitimado a resguardar a observância dos direitos fundamentais dos contribuintes, devendo ser previstos todos os meios processuais possíveis para que isso seja realizado, inclusive por meio da Ação Civil Pública.

No entanto, no caso dos direitos individuais homogêneos, o entendimento jurisprudencial atual defende que o Ministério Público somente terá legitimidade plena se esses direitos forem indisponíveis. Caso estes sejam disponíveis, o MP só terá legitimidade para ACP envolvendo direitos individuais homogêneos disponíveis se estes forem de interesse social (se houver relevância social), conforme se infere do julgado abaixo transcrito:

AĈ̃OCIVIL PÚBLICA-DIREITOS INDIVIDUAIS HOMOGÊNEOŚIDENTIFICÁVEISE DIVISÍVEIS-AUSÊNCIADERELEVANTE INTERESSE SOCIAL - ILEGITIMIDADE ATIVA AD CAUSAM DO MINISTÉRIO PÚBLICO RECONHECIDA - CARÊNCIA DECRETADA-DECISÃO MANTIDA-RECURSO IMPROVIDO. O Ministério Público não tem legitimidade para figurar no polo ativo de ação civil pública na hipótese de direitos individuais homogêneos,identificáveis e divisíveis, que devem ser postulados pelos seus próprios titulares. (TJ-SP - APL: 9093966492009826 SP 9093966-49.2009.8.26.0000, Relator: Renato Sartorelli, Data de Julgamento: 14/09/2011, 26a Câmara de Direito Privado, Data de Publicação: 19/09/2011) 
E para os Tribunais pátrios, mesmo havendo interesse social relevante na defesa dos direitos fundamentais dos contribuintes por meio da ação civil pública, já que esses direitos são atinentes a condição de pessoa humana, previstos na Carta Magna, devendo ser resguardados de todas as formas cabíveis a disposição expressa legal contida na LACP, inserida por Medida Provisória inconstitucional, tem o condão de promover a ilegitimidade do parquet para defender esses interesses em juízo.Para comprovar essa assertiva, cabe fazer o uso de mais um julgado:

EMENTA Agravo regimental no recurso extraordinário. Ação civil pública. Ministério Público Federal. Matéria tributária. Ilegitimidade ativa. 1. Ampliação dos limites estabelecidos em lei para a dedução da base de cálculo do IRPF. Jurisprudência assente no sentido de que falece ao Ministério Público legitimidade processual para, em ação civil pública, deduzir pretensão relativa a matéria de natureza tributária. 2 . Agravo regimental não provido. (STF - RE: 736365 SP , Relator: Min. DIAS TOFFOLI, Data de Julgamento: 28/10/2014, Primeira Turma, Data de Publicação: DJe-229 DIVULG 20-11-2014 PUBLIC 21-11-2014)

Apesar dessas premissas acima aventadas, se defende a legitimidade do $\mathrm{Mi}$ nistério Público para atuar no polo ativo da ação civil pública para discutir matéria tributária quando esta abarca a coletividade, tendo em vista a natureza jurídica dos valores fundamentais envolvidos nessa discussão, com base, notadamente, no disposto no artigo 81 do Código de Defesa do Consumidor, combinado com o artigo 129 da Constituição Federal.

Argumentos favoráveis à manutenção à limitação do alcance da ação civil pública à tutela dos direitos dos contribuintes:

Apesar da nítida inconstitucionalidade da MP 2180-35 de 2001, alguns doutrinadores sustentam que essa proibição encontra guarida na sistemática da lei da Ação Civil Pública.

No entendimento destes, o argumento da inadmissibilidade da propositura destas ações se assenta na absoluta ausência de previsão legislativa, na medida em que a Lei de Ação Civil Pública em momento algum autoriza uma interpretação ampliativa que legitime a propositura de ações civis coletivas de proteção de interesses disponíveis com origem comum. Também não há como se aceitar o argumento de que se trata de direito coletivo, uma vez que este tem uma natureza indivisível (CDC, art. 81, II).

Os direitos individuais homogêneos, ao contrário, podem ser individualmente reparados, de modo que são caracterizados pela divisibilidade. Não haveria, portanto, inconstitucionalidade, na medida em que o legislador apenas explicitou uma proibição que já fazia parte do próprio sistema, por razões de ordem prática. ${ }^{41}$

Este posicionamento mostra-se controvertido. Para boa parte da doutrina, o legislador, no Código de Defesa do Consumidor, não quis restringir a tutela coletiva acidental aos direitos consumeristas. Para discutir tal problemática é importante pontuar as razões de veto ${ }^{42}$ do artigo 89 do Projeto de Lei que deu origem 
à Lei $n^{\circ}$. 8.078, de 11 de setembro de 1990, o reconhecido Código de Defesa do Consumidor, conforme exarado na Mensagem de Veto $n^{\circ} .664$, de mesma data. ${ }^{43}$

O veto presidencial pontua que o CDC deve voltar-se às relações estritamente consumeristas, desprezando o microssistema da tutela coletiva e a vontade do legislador, que não quis fazer esta restrição, mas, em verdade, ampliar as situações fáticas que possam ser albergadas pela definição proposta no artigo 81, parágrafo único, III, conforme demonstrava o artigo 89, vetado. Conquanto tenha havido o referido veto presidencial, o espírito do legislador não pode ser esquecido. Ademais, essa justificativa se mostra incoerente, já que não havia limitação à tutela coletiva dos direitos individuais homogêneos antes de ter sido inserida na Lei $7.347 / 85$ a disposição constante do seu artigo $1^{\circ}$, parágrafo único. ${ }^{44}$

E não por coincidência, a alteração foi promovida no momento em que se multiplicavam valorosas iniciativas do Ministério Público e de associações civis representativas que, através de ações civis públicas, questionavam, com êxito junto ao Poder Judiciário, desmandos e arbitrariedades em matéria tributária. Ademais, o efeito erga omnes das decisões em ações civis públicas possibilitava a interrupção total e imediata do fluxo de recursos para os cofres públicos, oriundos de tributação ilegal impugnada nestas ações. Referidas intervenções, até então bem sucedidas, por óbvio, eram motivo de perturbação para um Poder Executivo habituado a promover exigências tributárias ilegais, combatidas por alguns poucos, sem reflexos significativos na arrecadação da exação. ${ }^{45}$

A garantia de acesso à justiça por meio do processo coletivo, instrumentalizada pela ação civil pública, na esfera tributária, tem escopo fundamental, em virtude da ínfima parcela de jurisdicionados que recorre ao Poder Judiciário contra exigências desta natureza. Os altos custos do processo e sua morosidade, as despesas com advogado, aliados muitas vezes aos baixos valores despendidos individualmente pelos contribuintes a título daquele tributo, são todos fatores que concorrem para o desencorajamento do cidadão em submeter ao crivo do Poder Judiciário a lesão a seu direito, ${ }^{46}$ que poderia ser tutelado na forma coletiva.

E isso denota como essa limitação do alcance da ação civil pública à tutela dos direitos dos contribuintes denota limitação do acesso à justiça por parte dos contribuintes, implicando em afronta ao direito fundamental previsto no inciso XXXV do artigo 5 da Constituição Federal, traduzindo exclusão da apreciação do Poder Judiciário a lesão ou ameaça a direito.

Infere-se, assim, que, apesar do entendimento majoritário da jurisprudência, que afasta o cabimento da ação civil pública na proteção dos direitos fundamentais dos contribuintes, esse entendimento deve urgentemente ser revisto, no sentido de admitir a ação civil pública em matéria tributária, pois a Constituição Federal atribuiu ao Ministério Público a defesa dos interesses coletivos e sociais. Por isso, uma Medida Provisória não poderia restringir e conceituar o que vem a ser interesses coletivos, impedindo o acesso à justiça por parte dos contribuintes. Ademais, a Lei da ação civil pública e o Código de Defesa 
do Consumidor constituem um microssistema que deve ser analisado e aplicado conjuntamente, e não isoladamente, tendo em vista o art. 21 da LACP e o art. 117 do CDC. Portanto, não há que se falar que não cabe ação civil pública na defesa dos interesses e direitos individuais homogêneos que não sejam consumidores. ${ }^{47}$

\section{CONCLUSÃO}

A par de todo o aqui analisado, conclui-se pela necessidade urgente da revisão do entendimento jurisprudencial que proíbe o acesso, com a declaração de inconstitucionalidade do paragrafo único do artigo 10 da Lei de Ação Civil Pública, já que originário de Medida Provisória claramente inconstitucional. Assim, a importância de enfrentar esse paradigma, é decorrente do fato de ele implicar na limitação do acesso à justiça que essa norma introduz a uma classe determinada de sujeitos, quais sejam, os contribuintes.

Da análise dos direitos fundamentais dos contribuintes, previstos a partir do artigo 150 da Constituição Federal, pode-se afirmar que os legisladores, seja na esfera federal, estadual ou municipal, ao fazer uso de suas competências tributárias, estão obrigados a respeitar os direitos e garantias individuais, de forma que o contribuinte tenha o direito de, ainda que tributado pela pessoa política competente, ter assegurados seus direitos públicos subjetivos, constitucionalmente garantidos.

O que se tentou provar a partir da análise dos direitos fundamentais realizada no trabalho é que sempre que um desses princípios fundamentais não é observado na instituição de um tributo, ou mesmo em sua fiscalização ou arrecadação, não será tão somente um individuo quem sofrerá com a mitigação de seus direitos fundamentais, já que a obrigação tributária deve ser adimplida por todos aqueles que se encontram na situação descrita na hipótese de incidência. Assim, devem ser proporcionados, na legislação brasileira, formas de defesa coletiva, de acesso coletivo ao Judiciário para proteção desses direitos.

A ação civil pública serviria perfeitamente para esse fim, se não fosse a proibição trazida pelo paragrafo único do artigo $1^{\circ}$ da Lei $7347 / 85$, inserido pela Medida Provisória 2180-35 de 2001, que torna incabível ação civil pública para veicular pretensões que envolvam tributos, contribuições previdenciárias, $\mathrm{O}$ Fundo de Garantia do Tempo de Serviço - FGTS ou outros fundos de natureza institucional cujos beneficiários podem ser individualmente determinados.

Essa medida provisória se mostra eivada de nítida inconstitucionalidade, e acaba por restringir injustamente o acesso à justiça por parte daqueles que tem sua esfera de direitos fundamentais lesada. Isso porque ela é contrária ao disposto no artigo 62 da Constituição Federal de 1988, que disciplina ser vedada a edição de medidas provisórias sobre matéria direito penal, processual penal e processual civil. Tendo em vista que a Lei de Ação Civil Pública traz normas sobre o direito processual civil coletivo, esta medida provisória apresenta legítima afronta ao texto maior. 
Do todo até aqui exposto, percebe-se que o entendimento mais benéfico ao contribuinte é aquele que, pautado na origem individual homogênea dos direitos fundamentais tributários, que imprime ampla relevância social à defesa coletiva desses direitos, permite a utilização da ação civil pública para essa tutela, e entende como legitimado o Ministério Público. No entanto, para o revés do contribuinte, não é esse o entendimento dos tribunais pátrios, que, com base em uma disposição inconstitucional, preferem decidir com base na letra da lei, mesmo que esta represente nítida limitação do acesso à justiça para uma classe determinada de sujeitos.

\section{REFERÊNCIAS}

ALMEIDA, João Batista de. Aspectos controvertidos da ação civil pública. São Paulo: Revista dos Tribunais, 2001.

ALMEIDA, Gregório Assagra de. Direito Processual Coletivo Brasileiro: um novo ramo do direito processual (princípios, regras interpretativas e a problemática da sua interpretação e aplicação). São Paulo: Saraiva, 2003.

Direito processual coletivo brasileiro: um novo ramo do direito processual. São Paulo: Saraiva, 2003.

APPIO, Eduardo. A Ação Civil Pública no Estado Democrático de Direito. Curitiba: Juruá, 2007.

ARAÚJO FILHO, Luiz Paulo da Silva. Ações Coletivas: A tutela dos Direitos Individuais Homogêneos. Rio de Janeiro: Forense, 2000.

BARROSO, Luís Roberto. O direito constitucional e a efetividade de suas normas: Limites e possibilidades da constituição brasileira. Rio de Janeiro: Renovar, 2006.

BERALDO, Leonardo de Faria. A Ação Civil Pública em matéria tributária: legitimidade e aspectos polêmicos. RKL Advocacia. 15 jun. 2011. Disponível em: <http://www.rkladvocacia.com/arquivos/artigos/art_srt_arquivo20130420143546.pdf>. Acesso em: 20 out. 2015.

BONAVIDES, Paulo. Curso de direito constitucional. São Paulo: Malheiros, 2000.

CAMPOS, Gabriel Gealh de. Violação dos direitos e garantias individuais do contribuinte na atividade fiscalizadora da administração tributária. Revista de Direito Público, Londrina, V. 4, n. 1, pp. 219-235, jan/abr. 2009.

CAPPELLETTI, Mauro; GARTH, Bryant. In: NORTHFLEET, Ellen Gracie (Trad.). Acesso à Justiça. Porto Alegre: Sérgio Antônio Fabris Editor, 1988.

CARVALHO, Camilo de Oliveira. Acesso à justiça e tutela dos direitos individuais homogêneos: a inconstitucionalidade de paragrafo único do artigo $1^{\circ}$ da Lei da Ação Civil Pública. Disponível em: <https://s3.amazonaws.com/conpedi2/ anteriores/XIX+Encontro+Nacional+-+UFC-Fortaleza+(09\%2C+10\%2C+11+e $+12+d e+$ junho + de+2010).pdf $>$. Acesso em: 12 out. 2015. 
CASTILHO, Ricardo. Acesso à justiça: tutela coletiva de direitos pelo Ministério Público, Uma nova visão. São Paulo: Editora Atlas, 2006.

COSTA, Marcio Cesar. A responsabilidade Tributária de terceiros. São Paulo: Pontifícia Universidade Católica, 136 f. Dissertação (mestrado em direito). Pontifícia Universidade Católica: 2012.

COSTA, Regina Helena da. Curso de Direito Tributário. 4. ed. Saraiva: São Paulo, 2014.

DE LIMA, Manoel Cavalcante Neto. Direitos Fundamentais dos contribuintes como limitação ao poder de tributar. Carta Forense. São Paulo. 2014. Disponível em <http://www.cartaforense.com.br/conteudo/artigos/direitos-fundamentais-dos-contribuintes-como-limitacao-ao-poder-de-tributar/5650>. Acesso em: 10 out. 2015.

DIDIER JR., Fredie; ZANETI JR., Hermes. Curso de Direito Processual Civil: Processo Coletivo. 3. ed. Salvador: Editora Podivm, 2013, v. 4.

DINAMARCO, Pedro Silva. Ação Civil Pública. São Paulo: Saraiva, 2000.

GEALH, Gabriel de Campos. Violação dos direitos e garantias individuais do contribuinte na atividade fiscalizadora da administração tributária. Revista de Direito Público. Londrina, v. 4, n. 1, p. 219-235, jan/abr. 2009, p. 48.

GRINOVER, Ada Pelegrini. Das class action for damages à ação de classe brasileira: os requisitos de admissibilidade. Revista Forense, Rio de Janeiro, v. 352, p. 3-14, out/dez 2000.

HARADA, Kiyoshi. Direito financeiro e tributário. 7. ed. São Paulo: Atlas, 2001. KOERNER, Andrei. Ordem política e sujeito de direito no debate sobre direitos humanos. Lua Nova, São Paulo, n. 57, p. 87-111, 2002. Disponível em <http://www.scielo.br/scielo.php? script=sci_arttext\&pid=S0102$-64452002000200005 \& \operatorname{lng}=p t \& n r m=i s o>$. Acessos em: 26 jun. 2015. http:// dx.doi.org/10.1590/S0102-64452002000200005>.

LENZA, Pedro. Teoria Geral da Ação Civil Pública. 2. ed. São Paulo: Revista dos Tribunais, 2005.

LOUREIRO, Caio Márcio. Ação Civil Pública e o Acesso à Justiça. São Paulo: Editora Método, 2004.

MACHADO SEGUNDO, Hugo de Brito. Direito tributário e financeiro. São Paulo: Atlas, 2005.

MACIEL JÚNIOR, V. P. Teoria do direto coletivo : direito ou interesse (difuso, coletivo e individual homogêneo)? In: Revista trabalhista: Direito e processo, v. 3, n. 9, p. 233-279, jan./mar. 2004, p. 250.

MANCUSO, Rodolfo de Camargo. Interesses Difusos: Conceito e Legitimação para Agir. 6.ed. rev. ampl. atual. São Paulo: Revista dos Tribunais, 2004.

MARINS, James. Princípios Fundamentais do Direito Processual Tributário. São Paulo: Dialética, 1998. 
MAZZILLI, Hugo Nigro. A Defesa dos Interesses Difusos em Juízo. São Paulo: Saraiva, 2002.

. O Inquérito Civil. 2. ed. São Paulo: Saraiva, 2000.

MEIRELLES, Hely Lopes; Wald, Arnoldo; Mendes, Gilmar Ferreira. Mandado de Segurança e Ações Constitucionais. 32. ed. São Paulo: Malheiros. 2009.

MENDES, Gilmar Ferreira. In: WALD, Arnoldo (Coord). Ação Civil Pública e controle de constitucionalidade: Aspectos Polêmicos da Ação Civil Pública. 2. ed. São Paulo: Saraiva. 2007.

NERY JUNIOR, Nelson. Princípios do Processo Civil na Constituição Federal. 8.ed. rev. atual. ampl. Coleção Estudos de Direito de Processo Enrico Tullio Liebman. São Paulo: Revista dos Tribunais, 2004, v. 21.

NEVES, Raphael. Uma Comissão da Verdade no Brasil? Desafios e perspectivas para integrar direitos humanos e democracia. Lua Nova, São Paulo, n. 86 p. 155-186, 2012. Disponível em: <http://www.scielo.br/scielo.php?script=sci_ arttext\&pid=S0102-64452012000200006\&lng=pt\&nrm=iso>. Acessos em: 26 jun. 2015.

ROCHA, L. V. Ações coletivas: o problema da legitimidade para agir. Rio de Janeiro: Forense, 2007.

SILVA, S. L. Elementos das ações coletivas. São Paulo: Método, 2004.

SILVEIRA, Sebastião Sérgio da; SILVEIRA, Ricardo dos Reis. Ação civil pública em matéria tributária, como instrumento de acesso à justiça. Conpedi. 15 de novembro de 2008. Publicadireito.com.br Disponível em: <http://www.publicadireito.com.br/artigos/?cod=f00ca20f88ef7d8e>. Acesso em: 22 jun. 2014.

SOUZA, Wilson Alves de. Acesso à Justiça e Responsabilidade Civil do Estado por sua denegação: Estudo Comparativo entre o Direito Brasileiro e o Direito Português. Tese de Pós-doutorado. Universidade de Coimbra. Coimbra: 2006.

VELLOSO, Carlos Mário da Silva. In: WALD, Arnoldo (Coord.). Processo judicial tributário: medidas judiciais que o integram e a legitimidade do Ministério Público para a ação civil pública que tem por objeto o não-pagamento de um tributo. Aspectos polêmicos da Ação Civil Pública. 2. ed. rev. atual. São Paulo: Saraiva, 2007.

VENTURI, Elton. Processo civil coletivo. São Paulo: Malheiros, 2007.

VIGLIAR, José Marcelo Menezes. Interesses Individuais Homogêneos e seus aspectos polêmicos. São Paulo: Saraiva, 2003.

WATANABE, Kazuo et al. Código Brasileiro de Defesa do Consumidor comentado pelos autores do Anteprojeto. 8. ed. rev.ampl. Rio de Janeiro: Forense Universitária, 2004.

ZAVASCKI, Teori Albino. Processo Coletivo. 4. ed. São Paulo: RT, 2009. 
1 BONAVIDES, Paulo. Curso de direito constitucional. São Paulo: Malheiros, 2000, p. 514-518.

2 CAMPOS, Gabriel Gealh de. Violação dos direitos e garantias individuais do contribuinte na atividade fiscalizadora da administração tributária. Revista de Direito Público, Londrina, V. 4, n. 1, pp. 219-235, jan/abr. 2009.

3 KOERNER, Andrei. Ordem política e sujeito de direito no debate sobre direitos humanos. Lua Nova, São Paulo, n. 57, p. 87-111, 2002 Disponível em <http://www.scielo.br/scielo.php?script=sci_ arttext\&pid=S0102-64452002000200005\&lng=pt\&nrm=iso>. Acessos em: 26. jun. 2015.

4 Ibid.

5 NEVES, Raphael. Uma Comissão da Verdade no Brasil? Desafios e perspectivas para integrar direitos humanos e democracia. Lua Nova, São Paulo, n. 86 p. 155-186, 2012. Disponível em: <http://www. scielo.br/scielo.php?script=sci_arttext\&pid=S0102-64452012000200006\&lng=pt\&nrm=iso>. Acesso em: 26 jun. 2015.

6 CARVALHO, Camilo de Oliveira. Acesso à justiça e tutela dos direitos individuais homogêneos: a inconstitucionalidade de paragrafo único do artigo $1^{\circ}$ da Lei da Ação Civil Pública. Disponível em $<$ https://s3.amazonaws.com/conpedi2/anteriores/XIX+Encontro+Nacional+-+UFC-Fortaleza+(09\%2C+1 $0 \% 2 \mathrm{C}+11+\mathrm{e}+12+\mathrm{de}+\mathrm{junho}+\mathrm{de}+2010) \cdot \mathrm{pdf}>$. Acesso em: 12 out. 2015.

7 GEALH, Gabriel de Campos. Violação dos direitos e garantias individuais do contribuinte na atividade fiscalizadora da administração tributária. Revista de Direito Público, Londrina, v. 4, n. 1, p. 219-235, jan/ abr. 2009, p. 48.

8 DE LIMA, Manoel Cavalcante Neto. Direitos Fundamentais dos contribuintes como limitação ao poder de tributar. Carta Forense. São Paulo. 2014. Disponível em $<$ http://www.cartaforense.com.br/conteudo/artigos/direitos-fundamentais-dos-contribuintes-como-limitacao-ao-poder-de-tributar/5650>. Acesso em: 10 out. 2015 .

9 Ibid.

10 Art. 97. Somente a lei pode estabelecer: I - a instituição de tributos, ou a sua extinção; II - a majoração de tributos, ou sua redução, ressalvado o disposto nos artigos 21, 26, 39, 57 e 65; III - a definição do fato gerador da obrigação tributária principal, ressalvado o disposto no inciso I do $\S 3^{\circ}$ do artigo 52 , e do seu sujeito passivo; IV - a fixação de alíquota do tributo e da sua base de cálculo, ressalvado o disposto nos artigos 21, 26, 39, 57 e 65; V - a cominação de penalidades para as ações ou omissões contrárias a seus dispositivos, ou para outras infrações nela definidas; VI - as hipóteses de exclusão, suspensão e extinção de créditos tributários, ou de dispensa ou redução de penalidades.

11 Art. 144. O lançamento reporta-se à data da ocorrência do fato gerador da obrigação e rege-se pela lei então vigente, ainda que posteriormente modificada ou revogada. § $1^{\circ}$ Aplica-se ao lançamento a legislação que, posteriormente à ocorrência do fato gerador da obrigação, tenha instituído novos critérios de apuração ou processos de fiscalização, ampliado os poderes de investigação das autoridades administrativas, ou outorgado ao crédito maiores garantias ou privilégios, exceto, neste último caso, para o efeito de atribuir responsabilidade tributária a terceiros.

12 COSTA, Regina Helena da. Curso de Direito Tributário. 4. ed. São Paulo: Saraiva, 2014, p. 401.

13 MACHADO, Hugo de Brito. Curso de Direito Tributário. 22. ed. São Paulo: Malheiros, 2003, p. 87.

14 COSTA, Marcio Cesar. A responsabilidade Tributária de terceiros. São Paulo: Pontifícia Universidade Católica, 136 f. Dissertação (mestrado em direito). Pontifícia Universidade Católica: 2012. p. 16.

15 Art. 113. A obrigação tributária é principal ou acessória. § 10 A obrigação principal surge com a ocorrência do fato gerador, tem por objeto o pagamento de tributo ou penalidade pecuniária e extingue-se juntamente com o crédito dela decorrente. $§ 2^{\circ}$ A obrigação acessória decorre da legislação tributária e tem por objeto as prestações, positivas ou negativas, nela previstas no interesse da arrecadação ou da fiscalização dos tributos. § $3^{\circ} \mathrm{A}$ obrigação acessória, pelo simples fato da sua inobservância, converte-se em obrigação principal relativamente à penalidade pecuniária.

16 COSTA, Regina Helena da. op. cit., p. 402.

17 DIDIER JÚNIOR, F., ZANETI JÚNIOR, H. Curso de Direito Processual Civil: Processo coletivo. v. 4. Salvador: Juspodivm, 2009, p. 81.

18 COSTA, Regina Helena da. op. cit., p. 403.

19 Ibid. 
20 Ibid.

21 Ibid.

22 BERALDO, Leonardo de Faria. A Ação Civil Pública em matéria tributária: legitimidade e aspectos polêmicos. RKL Advocacia. 15 de junho de 2011. Dísponível em <http://www.rkladvocacia.com/arquivos/artigos/art_srt_arquivo20130420143546.pdf> Acesso em 20 de outubro de 2015.

23 Ibid.

24 CARVALHO, Camilo de Oliveira. Acesso à justiça e tutela dos direitos individuais homogêneos: a inconstitucionalidade de paragrafo único do artigo $1^{\circ}$ da Lei da Ação Civil Pública. Conpedi. 12 de junho de 2010. Disponível em: <https://s3.amazonaws.com/conpedi2/anteriores/XIX+Encontro+Nacional+-+UFC-Fortaleza+(09\%2C+10\%2C+11+e+12+de+junho+de+2010).pdf>. Acesso em: 12 out. 2015.

25 DINAMARCO, Pedro Silva. Ação Civil Pública, São Paulo, Saraiva, 2000, p. 16

26 SILVEIRA, Sebastião Sérgio da; SILVEIRA, Ricardo dos Reis. Ação civil pública em matéria tributária, como instrumento de acesso à justiça. Conpedi. 15 de novembro de 2008. Disponível em: <http:// www.publicadireito.com.br/artigos/?cod=f00ca20f88ef7d8e> Acesso em: 22 jun. 2014.

27 DIDIER JÚNIOR, F., ZANETI JÚNIOR, H. Curso de Direito Processual Civil: Processo coletivo. v. 4. Salvador: Juspodivm, 2009. p. 73.

28 ALMEIDA, G. A. Direito processual coletivo brasileiro: um novo ramo do direito processual. São Paulo: Saraiva 2003, p. 488.

29 Isto é, os detentores do direito subjetivo que se pretende regrar e proteger são indeterminados e indetermináveis. Isso não quer dizer que alguma pessoa em particular não esteja sofrendo a ameaça ou o dano concretamente falando, mas apenas e tão-somente que se trata de uma espécie de direito que, apesar de atingir alguém em particular, merece especial guarida porque atinge simultaneamente a todos. (NUNES, R. As ações coletivas e as definições de direito difuso, coletivo e individual homogêneo. In: MAZZEI, R. e NOLASCO, R. D. (coord.). Processo Civil Coletivo. São Paulo: Quartier Latin, 2005, p. 86).

30 MANCUSO, R. C. Interesses difusos: conceito e legitimação para agir. São Paulo: RT. 2004. p. 94-95

31 MACIEL JÚNIOR, V. P. Teoria do direto coletivo: direito ou interesse (difuso, coletivo e individual homogêneo)? In: Revista trabalhista: direito e processo, v. 3, n. 9, p. 233-279, jan./mar 2004, p. 250.

32 ROCHA, L. V. Ações coletivas: o problema da legitimidade para agir. Rio de Janeiro: Forense, 2007, p. 53.

33 MAZZILI, H. N. A defesa dos interesses difusos em juízo. 20. ed. revista, ampliada e atualizada. São Paulo: Saraiva. 2007, p. 54-55.

34 SILVA, S. L. Elementos das ações coletivas. São Paulo: Método, 2004, p. 48.

35 SILVEIRA, Sebastião Sérgio da; SILVEIRA, Ricardo dos Reis. Ação civil pública em matéria tributária, como instrumento de acesso à justiça. Disponível em: <http://www.publicadireito.com.br/ artigos/?cod=f00ca20f88ef7d8e>. Acesso em: 22 jun. 2014.

36 BERALDO, Leonardo de Faria. op. cit.

37 Ibid.

38 Art. 50 Têm legitimidade para propor a ação principal e a ação cautelar: I - o Ministério Público; II - a Defensoria Pública; II - a União, os Estados, o Distrito Federal e os Municípios; IV - a autarquia, empresa pública, fundação ou sociedade de economia mista; $\mathrm{V}$ - a associação que, concomitantemente: a) esteja constituída há pelo menos 1 (um) ano nos termos da lei civil; b) inclua, entre suas finalidades institucionais, a proteção ao patrimônio público e social, ao meio ambiente, ao consumidor, à ordem econômica, à livre concorrência, aos direitos de grupos raciais, étnicos ou religiosos ou ao patrimônio artístico, estético, histórico, turístico e paisagístico.

39 Art. 82. Para os fins do art. 81, parágrafo único, são legitimados concorrentemente: II - a União, os Estados, os Municípios e o Distrito Federal; III - as entidades e órgãos da Administração Pública, direta ou indireta, ainda que sem personalidade jurídica, especificamente destinados à defesa dos interesses e direitos protegidos por este código; IV - as associações legalmente constituídas há pelo menos um ano e que incluam entre seus fins institucionais a defesa dos interesses e direitos protegidos por este código, dispensada a autorização assemblear.

40 Art. 5 São funções institucionais do Ministério Público da União: II - zelar pela observância dos princípios constitucionais relativos: a) ao sistema tributário, às limitações do poder de tributar, à repartição do 
poder impositivo e das receitas tributárias e aos direitos do contribuinte.

41 APPIO, Eduardo. A Ação Civil Pública no Estado Democrático de Direito. Curitiba: Juruá, 2007, p. 75.

42 EXCELENTÍSSIMO SENHOR PRESIDENTE DO SENADO FEDERAL: Tenho a honra de comunicar a Vossa Excelência que, nos termos do parágrafo $1^{\circ}$ do artigo 66 da Constituição Federal, resolvi vetar parcialmente o Projeto de Lei n 97/89 (n 3.683/89, na Câmara dos Deputados), que "dispõe sobre a proteção do consumidor e dá outras providências". Os dispositivos ora vetados, que considero contrários ao interesse público ou inconstitucionais, são os seguintes: [...] "Art. 89 - As normas deste Título aplicam-se, no que for cabível, a outros direitos ou interesses difusos, coletivos e individuais homogêneos, tratados coletivamente". A extensão das normas específicas destinadas à proteção dos direitos do consumidor a outras situações excede dos objetivos propostos no código, alcançando outras relações jurídicas não identificadas precisamente e que reclamam regulação própria e adequada. Nos termos do art. 48 do Ato das Disposições Constitucionais Transitórias, deve o legislador limitar-se a elaborar Código de Defesa do Consumidor. [...]"

43 CARVAlHO, Camilo de Oliveira. Op cit..

44 BERALDO, Leonardo de Faria. Op. Cit.

45 Ibid.

46 Ibid.

47 Ibid.

THE PUBLIC CIVIL SUIT IN FISCAL MATTERS AS AN INSTRUMENT OF ACCESS TO THE JUDICIAL SYSTEM AND PROTECTION OF FUNDAMENTAL RIGHTS OF TAXPAYERS

\begin{abstract}
The fundamental rights in fiscal matters work as a protective barrier against the state discretion. It imposes limits on taxing, and respect to the dignity of taxpayers. Given the nature of these rights, and their homogeneous character for individuals, taxpayers should have means of collective access to justice for the protection of these rights, which would turn the law more effective. The Public civil suit, disciplined by statute $7347 / 85$, is one of the tools to defend the diffuse rights, hampered by public or private action or omission. However, the Provisional Measure 2180-35, 2001, added a single paragraph in Article 1 of that law, forbidding civil suits action on claims involving taxes, social security contributions, the Guarantee Fund for Employees or other institutional funds whose beneficiaries can be individually determined. This measure is clearly unconstitutional, because it serves to limit access to judicial system, of those who have been harmed by the eagerness of the state for increasing tax income. With that in mind, the scope of this article is to examine the possibility of the institution of civil action on tax
\end{abstract}


matters as a mean of access to judicial system to defend the fundamental rights of taxpayers who are collectively injured by the government.

Keywords: Civil Public Action. Fundamental Rights. Access to the judicial system. Fiscal limits.

Submetido: 24 nov. 2015

Aprovado: 19 jan. 2016 